\title{
Da violência de gênero no contexto da pandemia da COVID-19: um diálogo à luz dos direitos humanos e da personalidade
}

\author{
Gender violence in the context of the COVID-19 pandemic: a dialogue in the light of \\ human and personality rights
}

Jamille Bernardes da Silveira Oliveira dos Santos Unicesumar

Mestra em Ciências Jurídicas pela Universidade Cesumar Advogada Moreira Sales/Paraná/Brasil jamillebernardes@gmail.com

Valéria Silva Galdino Cardin Unicesumar

Pós-Doutora em Direito pela Universidade de Lisboa Advogada

Docente da Universidade Estadual de Maringá e no Programa de Pós-graduação em Ciências Jurídicas pelo Centro Universitário de Maringá (UNICESUMAR) Maringá/Paraná/Brasil valeria@galdino.adv.br

Resumo: Desde o fim de 2019 o mundo se encontra alarmado pela disseminação do vírus da COVID19. Em virtude do alto grau de contágio da doença e visando evitar o colapso das redes públicas e privadas de saúde, a Organização Mundial da Saúde (OMS) afirmou que a melhor forma de enfrentamento da doença seria por meio de isolamento social. Em que pese a inegável necessidade de observância da orientação repassada pela OMS, a questão do isolamento social, dentre os seus muitos desdobramentos, acentuou o número de casos de violência contra a mulher. Deste modo, o presente artigo, por meio de pesquisa teórica, possui por objetivo analisar a violência de gênero e os reflexos causados pela pandemia da COVID-19 neste contexto, sob a perspectiva dos direitos humanos e da personalidade.

Palavras-chave: COVID-19; direitos da personalidade; direitos humanos; violência contra a mulher; violência de gênero.

Abstract: Since the end of 2019, the world has been alarmed by the spread of the COVID-19 virus. Due to the high degree of contagion of the disease and trying to avoid the colapse of public and private health system, the World Health Organization (WHO) stated that the best way to prevent the disease would be through social isolation. Despite the undeniable need to follow the guideliness passed on by the WHO, the issues of the social isolation, among its many consequences, accentuated the number of cases of violence against women. Therefore, this article, through theoretical research, aims to analyze the gender violence and the consequences caused by the COVID-19 pandemic in this context, in the perspective of the human and personality rights.

Keywords: COVID-19; personality rights; human rights; violence against women; gender violence.

\section{Para citar este artigo}

ABNT NBR 6023:2018

SANTOS, Jamille Bernardes da Silveira Oliveira dos; CARDIN, Valéria Silva Galdino. Da violência de gênero no contexto da pandemia da COVID-19: um diálogo à luz dos direitos humanos e da personalidade. Prisma Jurídico, São Paulo, v. 20, n. 1, p. 173-191, jan./jun. 2021. http://doi.org/10.5585/prismaj.v20n1.17975. 
SANTOS, Jamille Bernardes da Silveira Oliveira dos; CARDIN, Valéria Silva Galdino. Da violência de gênero no contexto da pandemia da COVID-19: um diálogo à luz dos direitos humanos e da

\section{Introdução}

No final do ano de 2019 o mundo foi abalado pela disseminação de uma nova doença a COVID-19 - causada pelo coronavírus SARS-CoV-2, que provoca um "quadro clínico que varia de infecções assintomáticas a quadros respiratórios graves", podendo, em casos graves, provocar a morte do paciente (BRASIL, 2020).

Em 18 de março de 2020, o Brasil confirmou o seu primeiro caso de COVID-19 e, até a data de 29 de maio de 2020, o país contava com cerca de 465.166 (quatrocentos e sessenta e cinco mil cento e sessenta e seis) casos confirmados e 27.878 (vinte e sete mil e oitocentos e setenta e oito) óbitos ${ }^{1}$.

Mais do que a taxa de mortalidade, a principal preocupação causada pela pandemia da COVID-19 sempre cingiu em torno do seu alto grau de contágio e, portanto, da possibilidade de crescimento exponencial do número de casos, o que poderia levar a um colapso mundial do sistema de saúde, afetando tanto a rede privada quanto pública.

Em decorrência disso, a Organização Mundial da Saúde (OMS) alertou que a principal forma de combate da doença seria por meio do isolamento social. Isto é, as pessoas deveriam ser orientadas a permanecer em suas residências, limitando ao máximo o contato com outros indivíduos. Até mesmo no setor comercial apenas as atividades essenciais deveriam permanecer funcionando.

Diante deste cenário, no Brasil, assim como em outros países afetados pela doença, decretou-se o fechamento do comércio; ordenou-se que escolas e universidades suspendessem suas atividades; empresas concederam férias coletivas para seus funcionários, tudo como medida para tentar evitar aglomerações e frear o avanço dos casos.

A citada medida de proteção contra a COVID-19, ainda que inquestionavelmente indispensável ao combate do avanço da doença, acarretou muitos desdobramentos em várias esferas da vida cotidiana, suscitando embates econômicos, políticos, sociais, jurídicos e questões éticas e morais.

Dentre os percalços causados pelo isolamento social, destaca-se como objeto de estudo do presente artigo o aumento do número de casos de violência de gênero, com destaque à violência contra a mulher, seja na modalidade física, moral, sexual, patrimonial ou psíquica, bem como a desigualdade de gênero.

\footnotetext{
${ }^{1}$ Os dados apresentados foram retirados do Painel de Controle do Coronavírus, administrado pelo Ministério da Saúde do Brasil e divulgado através do site https://covid.saude.gov.br/. Os dados são atualizados a cada 24 horas e, em virtude disso, recomenda-se que, quando da leitura do artigo, seja feita uma consulta ao site indicado para a atualização do novo número de casos e da taxa de mortalidade (BRASIL, 2020).
} 
A presente pesquisa se valerá de um diálogo com os direitos humanos e da personalidade como norte para demonstrar como o isolamento social escancarou a desigualdade de gênero e aumentou o número de casos de violência contra as mulheres.

Tem-se também por objetivo evidenciar como o discurso essencialmente patriarcal afeta a proteção dos direitos da personalidade das mulheres e a necessidade de políticas públicas para coibir as violências de gênero. Para tanto, far-se-á uso do método de pesquisa teórico, a partir do levantamento de artigos, livros, leis e reportagens relacionadas com a temática proposta.

\section{Sexo e gênero: da construção do ser homem e do ser mulher}

O conceito de sexo está relacionado a características biológicas e físicas capazes de diferenciar mulheres e homens. Enquanto estes últimos são dotados de aparelho reprodutor composto pelos "testículos, epidídimo, ducto deferente, vesículas seminais, próstata, glândulas bulbouretrais, escroto e pênis [...] as mulheres possuem um aparelho reprodutor dotado de ovários, tubas uterinas, útero, vagina e vulva" (LIMA et al., 2017, p. 35). Por sua vez, o "gênero não inclui apenas um estado biológico, como homem e mulher, mas também remete à questão do reconhecimento íntimo, à atribuição social, ou legal” (PAULA; VIEIRA, 2015, p. 73).

Joan Scott (1995, p. 72) discorre que o termo "gênero" passou a ser usado pelas feministas americanas como palavra-meio para destacar as diferenças entre homens e mulheres tão somente com base no sexo. Deste modo, a palavra gênero também pode ser empregada como "uma rejeição do determinismo biológico implícito no uso de termos como "sexo" ou "diferença sexual"'”.

Ainda hoje, uma vez determinado o sexo biológico do indivíduo, espera-se que este haja como pertencente a determinado gênero e se relacione, socialmente, de maneira específica quando contraposto com o gênero oposto (SPINOLA-CASTRO, 2005). Sexo é, “[...] desde sempre, marcado pelo gênero. Assim, os valores de quem olha e/ou classifica genitais interferem naquilo que estão vendo e, consequentemente, na nominação do que veem" (MACHADO, 2005, p. 2).

Para Guacira Lopes Louro (2004, p. 15) “a declaração ‘é uma menina!' ou 'é um menino!' [...] mais do que uma descrição, pode ser compreendida como uma definição ou decisão sobre um corpo". Isso porque a concepção do gênero como um elemento unicamente construído a partir do sexo biológico provoca uma série de expectativas a respeito de como homens e mulheres devem se portar. 
A atribuição aos indivíduos "do gênero masculino e feminino de maneira correspondente ao sexo biológico é efetuada antes mesmo do nascimento, constituindo-se a família como a primeira instância socializadora dos indivíduos” (LIMA et al., 2017, p. 36).

Corpos femininos são educados para serem submissos, em um processo de educação mais artificial, ou seja, meninas são criadas para serem princesas, meigas e gentis, enquanto o processo de educação masculina é mais agressivo e meninos são ensinados a serem valentões, conquistadores, que devem se sujar, enquanto meninas devem se manter sempre recatadas (LIMA et al., 2017).

O gênero não só compreendido a partir dos elementos que diferenciam homens de mulheres, mas também dos que deverão ser atribuídos à noção do que é ser mulher e o que é ser homem. "Em sua dimensão normativa, objeto da crítica feminista, o gênero aponta para indicadores daquilo que é entendido como coisa de homem ou de mulher, constituindo verdadeiro glossário orientador de nossos julgamentos" (GONÇALVES, 2020, p. 1).

O feminino e o masculino são criações socialmente impostas. O que se define como ‘coisa de menino' e 'coisa de menina' não passa de papéis socialmente aceitos e difundidos ao longo dos anos. Neste sentido, tem-se que "cada sociedade constrói padrões de comportamento para o masculino e feminino que extrapolam as diferenças sexuais, biológico-genéticas e organizam valores, normas e privilégios diferenciados" (ALMEIDA, 2010, p. 17).

Guacira Lopes Louro esclarece que as:

[...] diferenças entre os sexos e gêneros é sempre atribuída no interior de uma dada cultura; que determinadas características podem ser valorizadas como distintivas e fundamentais numa determinada sociedade; e ainda, que a nomeação da diferença é, ao mesmo tempo e sempre, a demarcação de uma fronteira (LOURO, 2012, p. 46).

Em decorrência do discurso patriarcal, é comum, social e culturalmente, que o homem seja "identificado nos músculos fortes e à mostra, no ser agressivo e autoritário, e a mulher é definida a partir de uma relação de oposição, frágil, emotiva, passiva, ingênua e dominável" (ALMEIDA, 2010, p. 102). Nota-se que o papel do sexo feminino é diretamente oposto ao papel atribuído ao ser homem (ALMEIDA, 2010).

Cumpre esclarecer que o patriarcado, segundo Carole Pateman (1993, p.167) é o poder natural "dos homens como indivíduos (sobre as mulheres) e abarca todos os aspectos da vida civil. A sociedade civil como um todo é patriarcal. As mulheres estão submetidas aos homens tanto na esfera privada quanto na pública”.

O patriarcalismo pode ser dividido em tradicional e moderno: o primeiro é datado da Idade Média até o século XVII, e corresponde ao poder do pai na família como reflexo de um 
modelo de relação de poder e autoridade; por sua vez, o patriarcado moderno se fixa nos direitos conjugais dos homens em relação às mulheres, e não mais, necessariamente, na figura do pai (NARVAZ; KOLLER, 2006).

Destaca-se que os papéis atribuídos a homens e mulheres são constantemente reforçados, seja por meio da verbalização do discurso, seja no modo de criação reproduzido no seio familiar ou no conteúdo midiático.

Anailde Almeida (2010, p. 103-104) em estudo intitulado "A construção social do ser homem e ser mulher", aborda a influência da TV na construção e no reforço dos papéis de gênero. A autora destaca a importância deste meio de comunicação como instrumento socializador, todavia, aponta que seu maior "sucesso está em reproduzir o arquétipo" culturalmente compreendido como sendo o papel social do homem e da mulher. Logo, a TV se ocupará de "reproduzir estereótipos sexuais" e de gênero socialmente aceitos.

Tem-se, deste modo, que "o gênero funciona como uma bússola que guia a compreensão social sobre como devem ser o masculino e o feminino, ao mesmo tempo diferenciando e reforçando a crença na estabilidade dessa diferenciação" (GONÇALVES, 2020, p. 1-2).

A desconstrução das oposições binárias "tornaria manifesta a interdependência e a fragmentação de cada um dos polos. Trabalhando para mostrar que cada polo carrega vestígios do outro e depende desse outro para adquirir sentido". A operação sugere também "o quanto cada polo é, em si mesmo, fragmentado e plural” (LOURO, 2004, p. 42-43).

Diante disto, vê-se que a noção do que é ser homem e do que é ser mulher não passa de uma construção social, muitas vezes, imposta. São reflexos deste contexto a negativa do reconhecimento das identidades e, lamentavelmente, na maioria das culturas, a manutenção da mulher em posição de inferioridade em relação ao homem, dando margem para que atrocidades históricas, como a caça às bruxas, ocorressem, bem como a violência contra a mulher.

Oportuno dizer que o determinismo sexual e de gênero não afeta só as mulheres, mas atrofia o reconhecimento e a conquista de direitos por minorias sexuais, entretanto, deixa-se de explorar esta questão para que seja possível centrar na temática proposta.

\section{Da violência de gênero em tempos de pandemia da COVID-19}

Desde o final de 2019, o mundo foi abalado pela disseminação do novo coronavírus. O primeiro caso de COVID-19 foi registado na China, em novembro de 2019 e, desde 11 de março 2020, a situação é considerada pela Organização Mundial da Saúde (OMS) como uma pandemia (GAZETA DO POVO, 2020; OPAS, 2020). O surto da doença "constitui uma Emergência de 
Saúde Pública de Importância Internacional - o mais alto nível de alerta da Organização, conforme previsto no Regulamento Sanitário Internacional” (OPAS, 2020).

Em decorrência deste cenário, em março de 2020, a Organização das Nações Unidas (ONU) divulgou um informativo em que alertava que, em decorrência da pandemia, houve aumento do número de casos de violência de gênero. De acordo com este documento "as mulheres continuam sendo as mais afetadas pelo trabalho não-remunerado, principalmente em tempos de crise" (ONU, 2020).

A ONU também destacou que, diante deste contexto de emergência, houve aumento do número de casos de violência contra as mulheres e meninas, em especial a violência doméstica, por conta das tensões no seio familiar provocadas pela pandemia (ONU, 2020). Destaca-se que a principal forma de combater a doença é por meio do isolamento social, o que faz com que as mulheres permaneçam mais tempo dentro dos lares.

Segundo Linda L. Dahlberg e Etienne G. Krug, a Organização Mundial da Saúde define violência como:

O uso de força física ou poder, em ameaça ou na prática, contra si próprio, outra pessoa ou contra um grupo ou comunidade, que resulte ou possa resultar em sofrimento, morte, dano psicológico, desenvolvimento prejudicado ou privação (DAHLBERG; KRUG, 2002, tradução livre) ${ }^{2}$.

A violência não é só o ato que causa algum dano físico, mas toda conduta que atente contra a dignidade de outra(s) pessoa(s), provocando-lhe(s) dano(s). Portanto, "a violência é uma relação de forças na qual há um desequilíbrio ou um abuso de poder. Caracteriza um estado de dominação e de expropriação quer de indivíduos, quer de grupos ou de classes sociais sobre outrem" (NARVAZ, 2005, p. 37).

A partir da década de 1990, em virtude dos estudos sobre gênero, o termo 'violência de gênero' passou a ser utilizado no lugar, ou como sinônimo, do termo 'violência contra mulher' (ARAÚJO, 2008). Deste modo, o termo violência de gênero abrange não só a violência contra a mulher, mas também a violência contra as crianças e adolescentes fruto do discurso patriarcal "que delega aos homens o direito de dominar e controlar suas mulheres, podendo, para isso, usar a violência" (ARAÚJO, 2008).

Joan Scott (1995) ao comentar sobre as raízes do patriarcado, faz referência a três autoras distintas: Mary O'Brien, que acreditava que a dominação masculina em relação às mulheres advinha de um desejo daqueles de se fazerem transcender dos mecanismos de

\footnotetext{
${ }^{2}$ No original: "The intentional use of physical force or power, threatened or actual, against oneself, another person, or against a group or community, that either results in or has a high likelihood of resulting in injury, death, psychological harm, maldevelopment or deprivation" (DAHLBERG; KRUG, 2002).
} 
reprodução da espécie, enquanto para Sulamith Firestone a libertação das mulheres poderia vir por meio dos avanços tecnológicos, os quais em breve poriam de lado a necessidade de corpos femininos para esse fim. Por último, Joan Scott menciona as ideias de Catjerine MacKinnon, a qual acreditava que a raiz do patriarcado se encontrava alinhada às raízes da sexualidade humana.

Para Maria de Fátima Araújo (2008) embora o sistema patriarcal tenha sido o foco dos estudos feministas no tocante às relações de dominação e submissão às quais as mulheres eram (e são) submetidas por parte dos homens, esta é uma visão criticada atualmente em virtude do seu viés universalizante. A autora destaca que a maneira como a dominação masculina se manifesta não é idêntica em todos os contextos, de forma que é necessário perceber que "há variações na forma como o poder patriarcal se institui e se legitima, assim como nas formas de resistência que as mulheres desenvolvem nos diferentes contextos" (ARAÚJO, 2008).

Os papéis sociais, como dito anteriormente, são marcados pelos discursos de gênero, diz-se que algo é de menina e aquilo se propaga e se enraíza socialmente como uma verdade. Ainda hoje, as identidades seguem marcadas pelo discurso patriarcal, o que implica reconhecer que os corpos são "demarcados e aprisionados pelo machismo, racismo e heterossexismo, que faz com que as pessoas se sintam inferiorizadas, diferenciadas e excluídas, 'fora' do que é dito 'aceito e normal'” (CAVALCANTI; REZENDE-CAMPOS, 2020, p. 13).

Para Gabriely Gomes dos Reis, a masculinidade como é pensada e praticada atualmente:

só contribui ainda mais para a expressão da agressividade, da desigualdade frente ao feminino, visto que desde pequeno, a família já impõe na criança a necessidade de afirmação do que é ser homem, por meio de condutas sociais que demarcam o ser masculino, gerando na maioria dos homens um sentimento de autoafirmação constante, pelo qual são levados a assumir posturas, comportamentos e até mesmo espaços que os aproximem do ideal da masculinidade que lhes foi conferida (REIS, 2019, p. 16).

Diante deste quadro, tem-se que "a ideologia de gênero é um dos principais fatores que levam as mulheres a permanecerem em uma relação abusiva. Muitas delas internalizam a dominação masculina como algo natural e não conseguem romper com a situação de violência e opressão em que vivem" (ARAÚJO, 2008).

Verifica-se que "a sociedade espera [...] que a mulher desempenhe, prioritariamente, o papel de esposa, mãe, dona de casa e, cumulativamente, o de profissional. Dessa situação se origina a dificuldade de conciliação entre o idealmente esperado versus os papéis efetivamente desempenhados" (ALMEIDA, 2010, p. 32). 
Importa reforçar que, conforme já esclarecido, a violência de gênero não atinge apenas as mulheres, mas as crianças e adolescentes e pessoas LGBTQIA $+^{3}$, os quais também se encontram em situação agravada diante do quadro global de pandemia, todavia, a presente pesquisa visa dar ênfase à violência contra a mulher.

De acordo com reportagem do Jornal Nacional, veiculada pelo site de notícias G1, em 26 de fevereiro de 2019, “em 2018, segundo um levantamento do Datafolha, encomendado pelo Fórum Brasileiro de Segurança Pública, 16 milhões de mulheres acima de 16 anos sofreram algum tipo de violência: $3 \%$ ao se divertir num bar, $8 \%$ no trabalho, $8 \%$ na internet, $29 \%$ na rua e $\mathbf{4 2 \%}$ em casa" (G1, 2019, grifo nosso). Diante dos dados acima, verifica-se que o local em que as mulheres mais sofrem violência é dentro de suas próprias casas, razão pela qual a orientação de isolamento social, em virtude da pandemia da COVID-19, representa um fator que corrobora com o aumento da violência contra a mulher.

Segundo o "Boletim Mulheres e seus Temas Emergentes", realizado pelo Observatório da Mulher contra a Violência e divulgado pelo Senado Federal em abril de 2020, no primeiro mês de isolamento social o Estado do Rio de Janeiro registrou um aumento de 50\% dos casos de violência contra a mulher (BRASIL, 2020). No Estado do Paraná "houve um aumento de $15 \%$ nos registros de violência doméstica atendidos pela Polícia Militar no primeiro fim de semana de isolamento" (BARONE, 2020).

Já uma reportagem divulgada pela Folha de São Paulo, em 15 de abril de 2020, apontou que da data "de 24 de março - data em que passou a valer o fechamento de comércios, bares e restaurantes do Estado [de São Paulo] - a 13 de abril, 16 mulheres foram assinadas dentro de casa"; em contrapartida, durante o mesmo período, em 2019, foram observados 9 feminicídios. De acordo com a reportagem, o "aumento do consumo de bebida alcóolica e a perda de renda de famílias ajudam a explicar tendência" do alto número de casos de violência contra as mulheres durante a pandemia (MARIANI; YUKARI; AMÂNCIO, 2020).

Outros fatores ligados ao aumento do número de casos de violência de gênero contra as mulheres durante o período de isolamento são o aumento do nível de estresse do agressor gerado pelo "medo de adoecer, a incerteza sobre o futuro, a impossibilidade de convívio social, a iminência de redução de renda - especialmente nas classes menos favorecidas, em que há grande parcela que sobrevive às custas do trabalho informal" (MARQUES et al., 2020).

Destaca-se como fator agravante a questão da "sobrecarga feminina com o trabalho doméstico e o cuidado com os filhos, idosos e doentes também pode reduzir sua capacidade de

${ }^{3}$ Lésbicas, Gays, Bissexuais, Travestis, Transgêneros, Transexuais, Queer, Intersexo, Assexuado e mais. 
evitar o conflito com o agressor", além de "torná-la mais vulnerável à violência psicológica e à coerção sexual" (MARQUES et al., 2020).

Neste ponto, observa-se que a própria sobrecarga de funções enfrentada pelas mulheres durante o período de isolamento social, além de corroborar para o aumento de casos de violência, evidencia a desigualdade de gênero caracterizada pela concepção e visão de mundo ultrapassada de que os cuidados com o lar e a casa correspondem tão somente às mulheres. A questão da "dependência financeira com relação ao companheiro em função da estagnação econômica e da impossibilidade do trabalho informal em função do período de quarentena é outro aspecto que reduz a possibilidade de rompimento da situação" (MARQUES et al., 2020).

Diante dos dados expostos, resta claro que a recomendação de isolamento social em decorrência da pandemia da COVID-19, embora necessária, deve ser encarada como um fator de risco no tocante à vulnerabilidade social da mulher, bem como quanto à violência de gênero, aqui expressa pelas agressões contra as mulheres, de modo que este cenário não só evidencia um problema de saúde pública, como deve ser interpretado como uma afronta aos direitos humanos e da personalidade das mulheres diante da ofensa à dignidade humana e o exercício do pleno desenvolvimento.

\title{
3 Da violência e da desigualdade de gênero como afronta aos direitos humanos e da personalidade
}

Com o fim da Segunda Guerra Mundial "a dignidade da pessoa humana foi evidenciada, em virtude da crueldade deixada pela guerra e atos desumanos ali praticados, tendo sido reconhecida em vários tratados internacionais, em diversos países do mundo" (SOUZA; FACHIN, 2019, p. 318). A partir disto, notou-se um movimento de busca pela proteção máxima da pessoa humana enquanto sujeito de direitos e detentora de dignidade, o que proporcionou o surgimento de uma categoria de direitos denominada 'direitos da personalidade'.

Para Patrícia Verônica Nunes Sobral de Souza e Zulmar Fachin:

\begin{abstract}
A Declaração Universal dos Direitos Humanos buscou uma melhoria nas relações entre todos os povos. Para tanto, foi elaborada uma Declaração cujos princípios democráticos estão inseridos em todas as Constituições do mundo moderno. A abordagem recai sobre a concepção de que ninguém pode ser forçado a escolher ou a abandonar uma crença, costume ou identidade, por quaisquer motivos. Isso porque se alguém é livre para pensar, é livre também para fazer escolhas. $\mathrm{O}$ que não se pode admitir é que imperem discriminação, intolerância, desigualdades e injustiças (SOUZA; FACHIN, 2019, p. 313).
\end{abstract}

A dignidade humana "tem sido o valor-guia de um processo de releitura dos variados setores do direito, que vão abandonando o liberalismo e o materialismo de outrora em favor da 
SANTOS, Jamille Bernardes da Silveira Oliveira dos; CARDIN, Valéria Silva Galdino. Da violência de gênero no contexto da pandemia da COVID-19: um diálogo à luz dos direitos humanos e da

personalidade

recuperação de uma abordagem mais humanista e mais solidária das relações jurídicas" (SCHREIBER, 2011, p. 7).

No contexto histórico, a noção jurídica de personalidade teve seu início no Direito Romano clássico e era compreendida como a qualidade daquele que reunisse em si três características: "status libertatis, status civitatis e o status familiae" (SOUSA, 1995, p. 47). Ou seja, a personalidade era atributo daquele que fosse reconhecido como livre, capaz de exercer atos na sociedade civil e membro pater familias (patriarca) ou que estivesse agindo sob os interesses de um grupo familiar. Por meio desta perspectiva, o Direito Romano estabeleceu a possibilidade de uma actio iniuriarum, a qual consistia na possibilidade de ingressar com uma ação contra todos os atos que atentassem contra a pessoa física ou a moral do cidadão (TEPEDINO, 2004).

A personalidade pode ser entendida como "uma estrutura dinâmica integrativa e integrante, que assegura uma unidade relativa e a continuidade no tempo do conjunto dos sistemas que explicam", bem como "as particularidades próprias de um indivíduo, de sua maneira de sentir, de pensar, de agir e de reagir em situações concretas" (VALLADON, 1988, p. 1). No âmbito jurídico, a personalidade é compreendida como a "faculdade, assegurada a qualquer pessoa, de que sua personalidade possa se desenvolver em seus aspectos físicos, psíquicos e morais, de forma plena e com a mais ampla liberdade possível" (BARRETO; SANTOS, 2006, p. 475).

A personalidade não constitui um direito em si, mas o meio pelo qual todos os demais institutos jurídicos encontram expressão. Gilberto Haddad Jabur (2020, p. 440) assevera que "a personalidade não é, nem tem direito. Dela, como ossatura, é que os jura decorrem e por causa dela é que também se reconhecem esses superlativos, mas não absolutos direitos".

Segundo Orlando Gomes (1974, p. 168) os direitos da personalidade são aqueles "considerados essenciais ao desenvolvimento da pessoa humana, que a doutrina moderna preconiza e disciplina, no corpo do Código Civil, como direitos absolutos. Destinam-se a resguardar a eminente dignidade da pessoa humana”. É a personalidade, portanto, um instrumento por meio do qual os demais direitos se manifestam.

De acordo com a Teoria Geral dos Direitos da Personalidade, o princípio da dignidade da pessoa humana (art. $1^{\circ}$, inciso III, da Constituição Federal de 1988), deve ser compreendido como uma cláusula geral desses direitos. Deste modo, esta teoria "pugna pelo reconhecimento de que a personalidade deve ser protegida de forma global, considerando a própria natureza da pessoa, que representa um valor unitário" (GARCIA, 2007, p. 73). Os direitos da personalidade dedicam-se a salvaguardar o que o indivíduo possui de mais valoroso: as características que o 
SANTOS, Jamille Bernardes da Silveira Oliveira dos; CARDIN, Valéria Silva Galdino. Da violência de gênero no contexto da pandemia da COVID-19: um diálogo à luz dos direitos humanos e da personalidade

permitem se conectar às demais pessoas, ao mesmo tempo em que consegue espaço para manifestar a sua individualidade enquanto ser dotado de racionalidade.

A Constituição Federal de 1988 evidenciou a necessidade de proteção à personalidade humana ao garantir direitos relativos ao nome, à honra, à intimidade, à imagem e à integridade física. Entretanto, somente com a entrada em vigor do Código Civil de 2002 é que a expressão "personalidade" foi incluída no arranjo jurídico brasileiro, em primeiro plano, como forma de delimitar o momento em que um ser passa a ter reconhecida a sua personalidade/existência, mesclando-se este conceito ao de capacidade civil e, posteriormente, o referido códex tratou de abarcar as características dos direitos da personalidade (BRASIL, 1988; BRASIL, 2002).

No tocante à dignidade da pessoa humana, Ingo Sarlet (2009, p. 47) discorre que esse instituto, enquanto uma “qualidade intrínseca da pessoa humana, é irrenunciável e inalienável, constituindo elemento que qualifica o ser humano como tal e dele não pode ser destacado [...]”. Nesse sentido, tem-se que a dignidade humana representa aquilo que o ser humano possui de mais íntimo, sem o qual, a sua própria existência restaria prejudicada.

Immanuel Kant (1997) leciona que, a dignidade é uma característica exclusiva do ser humano enquanto ser dotado de razão e capaz de possuir um fim em si mesmo. Para o autor, o ser humano não pode ser substituído por nada equivalente, motivo pelo qual não é possível lhe atribuir um preço, apenas valor, o qual se resume na constatação da sua dignidade (KANT, 1997). Deste modo, os direitos da personalidade compõem um conjunto de direitos sem os quais seria impossível o reconhecimento e a proteção da pessoa humana em sua totalidade.

A visão do princípio da dignidade da pessoa humana como cláusula geral dos direitos da personalidade impõe que o indivíduo deverá ser protegido em sua totalidade, ainda que o direito que julgue essencial à manutenção da sua dignidade não figure no rol de direitos reconhecidos como da personalidade.

Para Elimar Szaniawski, ainda que o ordenamento jurídico brasileiro tenha optado por descrever os direitos da personalidade de forma fragmentada (elegendo quais direitos condizem com a proteção da personalidade humana), ao prever a dignidade da pessoa humana como princípio essencial para a constituição do Estado Democrático de Direito, o legislador acabou por adotar uma tutela geral dos direitos da personalidade. Para o autor, "o princípio da dignidade da pessoa humana consiste, pois, no ponto nuclear, onde se desdobram todos os direitos fundamentais do ser humano" (SZANIAWSKI, 2005, p. 142).

A personalidade humana deve ser protegida em sua totalidade, isto é, a proteção jurídica não pode se limitar a salvaguardar apenas um número determinado de direitos, mas deve 
abranger toda e qualquer situação que se posicione de alguma forma contra a personalidade do indivíduo, posto que, em caso de lesão, a dignidade humana também restará prejudicada.

Conceituados os direitos da personalidade, passar-se-á à análise do conceito de violência contra a mulher. De acordo com a Lei no 11.340, de 7 de agosto de 2006 (Lei Maria da Penha), há 5 (cinco) modalidades de violência contra a mulher: a física, psicológica, sexual, patrimonial e a moral. De maneira resumida, a violência é entendida como aquela capaz de causar prejuízo à integridade física da mulher; por sua vez, a violência psicológica é entendida como aquela capaz de causar abalo emocional e/ou diminuição da autoestima, de maneira a interferir no pleno desenvolvimento da mulher (BRASIL, 2006).

Já a violência sexual é compreendida como toda conduta que afronte ou viole os direitos sexuais da mulher (aqui compreendidos pelo exercício do seu corpo e sexualidade, como por exemplo, ser forçada a manter relações sexuais ou ser impedida de utilizar métodos anticonceptivos) (BRASIL, 2006).

Enquanto a violência patrimonial é entendida como qualquer conduta que configure "retenção, subtração, destruição parcial ou total de seus objetos, instrumentos de trabalho, documentos pessoais, bens, valores e direitos ou recursos econômicos, incluindo os destinados a satisfazer suas necessidades" (BRASIL, 2006). Por fim, a violência moral se caracteriza por qualquer conduta praticada em desfavor da mulher que configure calúnia, difamação ou injúria (BRASIL, 2006).

De acordo com os dados apontados no tópico anterior, verifica-se que houve aumento do número de casos de violência contra a mulher durante a pandemia e o consequente isolamento social. Vê-se que os principais direitos da personalidade afetados pela questão da violência de gênero cingem em torno da integridade física, psíquica, moral e da dignidade sexual da mulher que, por derradeiro, atinge diretamente a sua personalidade, à medida que é afetada a sua dignidade e capacidade de pleno desenvolvimento (cláusula geral dos direitos da personalidade).

Verifica-se que a situação de violência enfrentada pelas mulheres, agravada pelo atual cenário global, decorre de uma desigualdade de gênero, pois conforme exposto ao longo do artigo, a violência de gênero é fruto de um discurso essencialmente patriarcal, em que, ao longo do contexto histórico e jurídico, a mulher sempre figurou numa posição de inferioridade em relação ao homem. A violência contra a mulher, além de ser uma afronta aos direitos da personalidade, representa uma ofensa aos direitos humanos, não apenas por violar a mulher enquanto sujeita de direitos, mas também em razão da desigualdade de gênero. 
No tocante à conquista de direitos por parte das mulheres, "a Declaração dos Direitos da Mulher e da Cidadã, escrita por Olympe de Gouges, em 1791, pode ser considerada a primeira manifestação feminista ao reivindicar que as mulheres fossem representadas como cidadãs [...]” (MELO, 2008, p. 561). Posteriormente, em 1948, embora a Declaração Universal dos Direitos Humanos tenha reconhecido que todos os seres humanos deveriam ser tratados enquanto pessoas livres e detentoras de direitos e dignidade, foi apenas em 1993, durante a Conferência Mundial de Direitos Humanos, realizada em Viena, é que restou reconhecida a inalienabilidade e indivisibilidade dos direitos humanos das mulheres do rol de direitos humanos e que lhes deveriam ser ofertadas iguais oportunidades de participação social, bem como erradicada toda e qualquer discriminação baseada no sexo (RIOS, 2006).

No Brasil, "a posição da mulher, na família e na sociedade em geral, desde a colonização até hoje, demonstra que a família patriarcal foi uma das matrizes de nossa organização social”. As mulheres brasileiras, "nas primeiras décadas do século XX, não haviam conquistado os direitos civis garantidos ao homem" (NARVAZ; KOLLER, 2006, p. 51).

A Constituição Federal de 1934 foi a primeira a possibilitar o reconhecimento da mulher enquanto sujeito de direitos, porquanto, em seu art. 113, afirmou que todos seriam vistos como iguais perante a lei, sem distinções de sexo, entre outros fatores ${ }^{4}$ (BRASIL, 1934). Entretanto, o Código Civil de 1916, revogado apenas em 2002, não reconhecia a autoridade da mulher enquanto esposa e mãe, fato que a colocava numa situação de inferioridade em relação ao homem/marido/pai, como se sua condição de sujeito de direitos dependesse do reconhecimento deste $^{5}$ (BRASIL, 1916). Inclusive, a incapacidade civil da mulher só foi retirada em 1962, com a entrada em vigor do Estatuto da Mulher Casada (TEDESCHI; COLLING, 2014).

Outro reflexo disso pode ser observado no tocante ao instituto do poder familiar, que até a mudança do Código Civil era denominado 'pátrio poder', em clara referência às concepções patriarcais, cujo discurso era de que apenas o homem possuía poderes e era visto como detentor de direitos.

Para Talita Rampin e José Carlos Freitas:

\footnotetext{
${ }^{4}$ Art. 113, CF/1934: “A Constituição assegura a brasileiros e estrangeiros residentes no país a inviolabilidade dos direitos concernentes á liberdade, á subsistência, á segurança individual e á propriedade, nos termos seguintes: 1) Todos são iguais perante a lei. Não haverá distinções, por motivo de nascimento, sexo, raça, profissões próprias ou dos paes, classe social, riqueza, crenças religiosas ou ideias políticas" (BRASIL, 1934, grifo nosso).

${ }^{5}$ Art. 380, do Código Civil de 1916: "Durante o casamento, exerce o pátrio poder o marido, como chefe da família (art. 233), e, na falta ou impedimento seu, a mulher" (BRASIL, 1916).
} 
o estigma da mulher enquanto fêmea, reprodutora, refletiu diretamente no modo pelo qual a sociedade passou a encará-la: ao homem, 'o plantador de sementes', coube a arte da guerra, da vida pública, da ciência, do desenvolvimento, afinal, é ele um desbravador, à mulher, coube a arte da procriação, da criação da prole, da manutenção do lar, do âmbito privado, particular, no qual ela, 'fêmea', 'reina'. O estigma da mulher é tamanho que, antes de 'ser-humano', é esposa, filha, mãe: apêndice. Sendo múltipla, múltiplos também são os reflexos e dores por ela sentido quando encarcerada (RAMPIN; FREITAS, 2012, p. 56).

Essa situação de invisibilidade jurídica da mulher, bem como a questão da ideologia que prega a superioridade do gênero masculino em relação ao feminino, permitiu que se instaurasse socialmente um quadro de vulnerabilidade da mulher em relação ao homem, sendo esta, constantemente, vítima das mais variadas agressões dentro e fora do lar, o que apenas se acentuou com a pandemia da COVID-19.

\section{Considerações finais}

A violência de gênero, aqui retratada com a violência contra a mulher, pode ser encarada como um problema que decorre do discurso patriarcal, pelo qual a mulher é vista como sexo e gênero inferior ao homem e, por isso, figura em relação de subordinação em comparação a este.

A questão da violência contra mulher não é apenas uma situação social, mas decorre de um contexto jurídico onde, por muitos anos, a mulher foi negligenciada enquanto sujeito de direitos e, até hoje, luta por uma igualdade de gênero efetiva, que ultrapasse o campo do discurso dos direitos humanos e atinja a realidade fática. A mulher, social e juridicamente, sempre careceu de reconhecimento enquanto indivíduo, porquanto, sempre esteve ofuscada pelos papéis a ela impostos. A sociedade e o Direito sempre viram a esposa, a mãe, entretanto, possuem dificuldade em reconhecer a mulher enquanto sujeito de direitos por si só.

A Lei Maria da Penha, por exemplo, apenas foi criada em 2006 (há menos de 20 anos), em decorrência do Brasil ter sido punido internacionalmente em caso que apurava uma denúncia de violência contra mulher. Além disso, até 2002, o Código Civil atrelava a validade do casamento à condição da mulher ser virgem, isto é, caso essa não fosse mais virgem na data do casamento o homem poderia solicitar a anulação do casamento.

Verifica-se que, no atual contexto, o aumento da violência contra a mulher se configura como um dos muitos problemas causados pela pandemia da COVID-19, isso porque a orientação pelo isolamento social contribuiu para intensificar a convivência dentro dos lares, sendo este o local onde mais ocorrem os casos de violência contra a mulher6́.

\footnotetext{
${ }^{6}$ Segundo reportagem divulgada pelo Instituto de Pesquisa Econômica Aplicada (IPEA) em 2019, em 43,1\% dos casos, a violência ocorre tipicamente na residência da mulher (IPEA, 2019).
} 
Recorda-se também que a sobrecarga de tarefas domésticas, segundo a ONU Mulheres (2020) também aumentou nesse cenário de pandemia, circunstância essa que deve, igualmente, ser considerada como uma modalidade de violência contra a mulher, porquanto, afeta diretamente o seu desenvolvimento psicológico.

A violência contra a mulher, em qualquer uma de suas modalidades, configura um atentado à dignidade e ao pleno desenvolvimento desta, isso quando não lhe retira o bem jurídico maior - a vida. Diante do quadro de violência contra a mulher, em especial o observado durante este período de isolamento social, é de suma importância que o Estado intensifique a propagação de informações referentes aos direitos das mulheres e os meios pelo quais podem ser feitas as denúncias de agressão contra as mulheres.

Ressalta-se que a violência contra a mulher é uma questão de ordem jurídica, social e de saúde pública. Assim, da mesma forma que são amplamente divulgadas as condutas de higienização necessárias para evitar o contágio e a transmissão da COVID-19, visto que a violência contra a mulher é uma situação agravada pelo quadro da pandemia, é de extrema urgência que os meios de comunicação informem também os mecanismos de combate à violência contra a mulher.

A longo prazo, este reflexo negativo causado pela recomendação de isolamento social deve servir para que o direito avance no que tange à proteção dos direitos das mulheres, a iniciar pela erradicação de toda forma de desigualdade de gênero. Destaca-se, neste ponto, a importância da representatividade da mulher na política como fator crucial para o avanço dos direitos das mulheres e para o fim da desigualdade de gênero.

\section{Referências}

ALMEIDA, Anailde. A construção social do ser homem e ser mulher. Salvador: EDUNEB, 2010 .

ARAÚJO, Maria de Fátima. Gênero e violência contra a mulher: o perigoso jogo de poder e dominação. Psicologia para América Latina, n. 14, out. 2008. Disponível em http://pepsic.bvsalud.org/scielo.php?script=sci_arttext\&pid=S1870$350 X 2008000300012 \& \operatorname{lng}=$ pt\&nrm=iso. Acesso em: 3 jun. 2020.

BARONE, Isabelle. Coronavírus: denúncias de violência doméstica aumentam e expõem impacto social da quarentena. Gazeta do Povo, 28 mar. 2020. Disponível em: https://www.gazetadopovo.com.br/vida-e-cidadania/coronavirus-denuncias-de-violenciadomestica-aumentam-e-expoem-impacto-social-da-quarentena/. Acesso em: 15 jun. 2020.

BARRETO, Wanderlei de Paula; SANTOS, Luciany Michelli Pereira dos. O conceito aberto de desdobramento da personalidade e os seus elementos constitutivos nas situações de mobbing ou assédio moral. Revista Jurídica Cesumar - Mestrado, Maringá, v. 6, n. 1, p. 
SANTOS, Jamille Bernardes da Silveira Oliveira dos; CARIDIN, Valéria Silva Galdino. Da violência de gênero no contexto da pandemia da COVID-19: um diálogo à luz dos direitos humanos e da

473-487, dez. 2006. Disponível em:

https://periodicos.unicesumar.edu.br/index.php/revjuridica/a rticle/view/322/181. Acesso em: 20 jan. 2020.

BRASIL. [Constituição (1988)]. Constituição da República Federativa do Brasil de 1988. Brasília, DF: Presidência da República, [2016]. Disponível em:

http://www.planalto.gov.br/ccivil_03/constituicao/constituicao.htm. Acesso em: 21 jan. 2020.

BRASIL. Lei $n^{0}$ 3.071, de $1^{\circ}$ de janeiro de 1916. Institui o Código Civil Brasileiro. Rio de Janeiro, DF: Presidência da República, [1916]. Disponível em:

https://www2.camara.leg.br/legin/fed/lei/1910-1919/lei-3071-1-janeiro-1916-397989publicacaooriginal-1-pl.html. Acesso em: 24 abr. 2020.

BRASIL. Lei no 10.406, de 10 de janeiro de 2002. Institui o Código Civil. Brasília, DF: Presidência da República, [2002]. Disponível em:

http://www.planalto.gov.br/ccivil_03/leis/2002/110406.htm. Acesso em: 8 jan. 2020.

BRASIL. Lei $\mathbf{n}^{\mathbf{0}}$ 11.340, de 7 de agosto de 2006. Cria mecanismos para coibir a violência doméstica e familiar contra a mulher, nos termos do $\S 8^{\circ}$ do art. 226 da Constituição Federal, da Convenção sobre a Eliminação de Todas as Formas de Discriminação contra as Mulheres e da Convenção Interamericana para Prevenir, Punir e Erradicar a Violência contra a Mulher; dispõe sobre a criação dos Juizados de Violência Doméstica e Familiar contra a Mulher; altera o Código de Processo Penal, o Código Penal e a Lei de Execução Penal; e dá outras providências. Brasília, DF: Presidência da República, [2006]. Disponível em: http://www.planalto.gov.br/ccivil_03/_ato2004-2006/2006/lei/111340.htm. Acesso em: 15 jun. 2020.

BRASIL. Ministério da Saúde. COVID-19. Painel Coronavírus. Brasília, DF: Ministério da Saúde, [2020]. Disponível em: https://covid.saude.gov.br/. Acesso em: 1 jun. 2020.

CAVALCANTI, Vanessa Ribeiro Simon; REZENDE-CAMPOS, Pollyanna. Sexualidades e gêneros dissidentes no espaço escolar: dimensões possíveis da educação para e pelos direitos humanos. Revista Direito e Sexualidade, v. 1, n. 1, p. 1-19, maio 2020. Disponível em: https://portalseer.ufba.br/index.php/revdirsex/article/view/35853/21090. Acesso em: 7 jun. 2020.

DAHLBERG, Linda L.; KRUG, Etienne G. Violence: a global public health problem. In: WORLD HEALTH ORGANIZATION (WHO). Global consultation on violence and health. Genova: WHO, 2002. Disponível em:

https://www.who.int/violence_injury_prevention/violence/world_report/en/FullWRVH.pdf. Acesso em: 14 jun. 2020.

GARCIA, Enéas Costa. Direito geral da personalidade no sistema jurídico brasileiro. São Paulo: Juarez de Oliveira, 2007.

GOMES, Orlando. Introdução ao direito civil. Rio de Janeiro: Forense, 1974.

GONÇALVES, Camila de Jesus Mello. Igualdade de gênero no Poder Judiciário: uma proposta de ação afirmativa. Revista Direito e Sexualidade, n. 1, p. 1-14, maio 2020. 
SANTOS, Jamille Bernardes da Silveira Oliveira dos; CARDIN, Valéria Silva Galdino. Da violência de gênero no contexto da pandemia da COVID-19: um diálogo à luz dos direitos humanos e da personalidade

Disponível em: https://portalseer.ufba.br/index.php/revdirsex/article/view/36800/21091. Acesso em: 07 jun. 2020.

ÍNDICE de violência doméstica é maior para mulheres economicamente ativas. IPEA, 19 ago. 2019. Disponível em:

https://www.ipea.gov.br/portal/index.php?option=com_content $\&$ view=article \&id=34977. Acesso em: 4 fev. 2020.

KANT, Immanuel. Fundamentação da metafísica dos costumes. Tradução: Paulo Quintela. Lisboa: Edições 70, 1997.

LIMA, Flaviane Izidro Alves de et al. A influência da construção de papeis sociais de gênero na escolha profissional. Revista Brasileira de Psicologia e Educação, Araraquara, v. 19, n. 1, p. 33-50, jan./jun. 2017. Disponível em:

https://periodicos.fclar.unesp.br/doxa/article/view/10818. Acesso em: 31 maio 2020.

LOURO, Guacira Lopes Louro. Um corpo estranho: ensaios sobre a sexualidade e a teoria queer. Belo Horizonte: Autêntica, 2004.

LOURO, Guacira Lopes. Currículo, gênero e sexualidade: o "normal", o "diferente" e o "excêntrico". In: LOURO, Guacira Lopes; NECKEL, Jane Felipe; GOELLNER, Silvana Vilodre (org.). Corpo, gênero e sexualidade: um debate contemporâneo na educação. 8. ed. Petrópolis: Vozes, 2012. p. 41-52.

MACHADO, Paula Sandrine. O sexo dos anjos: um olhar sobre a anatomia e a produção do sexo (como se fosse) natural. Cadernos Pagu, n. 24, p. 249-281, jan./jun. 2005. Disponível em: https://www.scielo.br/scielo.php?pid=S0104-

$83332005000100012 \&$ script=sci_abstract\&tlng=pt. Acesso em: 31 maio 2020.

MAIS de 500 mulheres são agredidas a cada hora no Brasil, diz pesquisa. G1, 26 fev. 2019. Disponível em: https://g1.globo.com/jornal-nacional/noticia/2019/02/26/mais-de-500mulheres-sao-agredidas-a-cada-hora-no-brasil-diz-pesquisa.ghtml. Acesso em: 15 jun. 2020.

MARIANI, Daniel; YUKARI, Diana; AMÂNCIO, Thiago. Assassinatos de mulheres em casa dobram em SP durante a quarentena por coronavírus. Folha de São Paulo, São Paulo, 15 abr. 2020. Disponível em: https://www1.folha.uol.com.br/cotidiano/2020/04/assassinatos-demulheres-em-casa-dobram-em-sp-durante-quarentena-por-coronavirus.shtml. Acesso em: 15 jun. 2020.

MARQUES, Emanuele Souza et al. A violência contra mulheres, crianças e adolescentes em tempos de pandemia pela COVID-19: panorama, motivações e formas de enfrentamento.

Cadernos de Saúde Pública, v. 36, n. 4, p. 1-6, 30 abr. 2020. Disponível em:

https://www.scielosp.org/article/csp/2020.v36n4/e00074420/\#. Acesso em: 15 jun. 2020.

MELO, Érica. Feminismo: velhos e novos dilemas uma contribuição de Joan Scott. Cadernos

Pagu, Campinas, n. 31, p. 553-564, dez. 2008. Disponível em;

http://www.scielo.br/scielo.php?script=sci_arttext\&pid=S0104-

$83332008000200024 \& \operatorname{lng}=e n \& n r m=i s o$. Acesso em: 6 jun. 2020. 
NARVAZ, Martha. Submissão e resistência: explodindo o discurso patriarcal da dominação feminina. 2005. 197 f. Dissertação (Mestrado em Psicologia) - Instituto de Psicologia, Universidade Federal do Rio Grande do Sul, Porto Alegre, 2005. Disponível em: https://lume.ufrgs.br/handle/10183/5442. Acesso em: 7 jun. 2020.

NARVAZ, Martha Giude; KOLLER, Sílvia Helena. Famílias e patriarcado: da prescrição normativa à subversão criativa. Revista Psicologia \& Sociedade, v. 18, n. 1, p. 49-55, jan./abr. 2006. Disponível em:

https://www.scielo.br/scielo.php?script=sci_arttext\&pid=S0102-71822006000100007. Acesso em: 7 jun. 2020.

ORGANIZAÇÃO DAS NAÇÕES UNIDAS (ONU). ONU Mulheres. Gênero e COVID-19 na América Latina e no Caribe. Brasília, DF: ONU, [2020]. Disponível em: http://www.onumulheres.org.br/wp-content/uploads/2020/03/ONU-MULHERESCOVID19_LAC.pdf. Acesso em: 4 jun. 2020.

ORGANIZAÇÃO PAN-AMERICANA DA SAÚDE (OPAS). Folha informativa sobre COVID-19. Histórico da pandemia de COVID-19. OPAS, 4 jun. 2020.Disponível: https://www.paho.org/bra/index.php?option=com_content\&view=article\&id=6101:covid19\&I temid=875. Acesso em: 7 jun. 2020.

PATEMAN, Carole. O contrato sexual. Rio de Janeiro: Paz e Terra, 1993.

PAULA, Ana Amélia Oliveira Reis de; VIEIRA, Márcia Maria Rosa. Intersexualidade: uma clínica da singularidade. Revista Bioética, v. 23, n. 1, p. 70-79, jan./abr. 2015. Disponível em: http://www.scielo.br/scielo.php?script=sci_arttext\&pid=S1983-

$80422015000100070 \& \operatorname{lng}=$ pt\&tlng=pt. Acesso em: 31 maio 2020.

PRIMEIRO caso do novo coronavírus no mundo teria ocorrido em novembro. Gazeta do Povo, 13 mar. 2020. Disponível em: https://www.gazetadopovo.com.br/mundo/primeirocaso-novo-coronavirus/. Acesso em: 15 maio 2020.

RAMPIN, Talita Tatiana Dias; FREITAS, José Carlos Garcia de. Gênero e direito: uma análise do princípio constitucional da igualdade. In: BRUNS, Maria Alves de Toledo; SOUZA-LEITE, Célia Regina Vieira de (orgs.). Gênero, diversidades e direitos sexuais nos laços da inclusão. Curitiba: CRV, 2012. p. 39-60.

REIS, Gabrielly Gomes dos. Implicações decorrentes das diferenças de gênero para a prática de professores do sexo masculino na educação infantil. 2019. $71 \mathrm{f}$. Monografia (Licenciatura em Pedagogia) - Faculdade de Pedagogia, Universidade Federal do Pará, Castanhal, 2019. Disponível em:

https://bdm.ufpa.br:8443/jspui/bitstream/prefix/2124/1/TCC_ImplicacoesDecorrentesDiferenc as.pdf. Acesso em: 31 maio 2020.

RIOS, Roger Raupp. Para um direito democrático da sexualidade. Horizontes Antropológicos, Porto Alegre, ano 12, n. 26, p. 71-100, jul./dez. 2006. Disponível em: https://www.scielo.br/scielo.php?script=sci_arttext\&pid=S0104-71832006000200004. Acesso em: 30 abril 2020. 
SARLET, Ingo Wolgang. Dignidade da pessoa humana e direitos fundamentais na Constituição Federal de 1998. 7ª . ed. Porto Alegre: Livraria do Advogado, 2009.

SCOTT, Joan. Gênero: uma categoria útil de análise histórica. Traduzido por Guacira Lopes Louro. Educação \& Realidade, v. 20, n. 2, p. 71-99, jul./dez. 1995. Disponível em: https://seer.ufrgs.br/index.php/educacaoerealidade/article/view/71721. Acesso em: 5 de jun. 2020.

SOUSA, Rabindranath Valentino Aleixo Capelo de. Direito geral de personalidade. Coimbra: Coimbra, 1995.

SOUZA, Patrícia Verônica Nunes Sobral de; FACHIN, Zulmar. O princípio da dignidade humana como fundamento para o Estado Contemporâneo: um olhar sob o viés dos direitos da personalidade. Revista de Direitos Sociais e Políticas Públicas (UNIFAFIBE), v. 7, n. 3, p. 311-340, 2019. Disponível em: www . unifafibe . com . br / revista / index . php / direitos sociais - politicas - pub / index. Acesso em: 24 jan. 2020.

SPINOLA-CASTRO, Angela Maria. A importância dos aspectos éticos e psicológicos na abordagem do intersexo. Arquivos Brasileiros de Endocrinologia \& Metabologia, São Paulo, v. 49, n. 1, p. 46-59, 2005. Disponível em:

http://www.repositorio.unifesp.br/handle/11600/2427. Acesso em: 31 maio 2020.

SZANIAWSKI, Elimar. Direitos da personalidade e sua tutela. 2. ed. São Paulo: Revista dos Tribunais, 2005.

TEDESCHI, Losandro Antônio; COLLING, Ana Maria. Os direitos humanos e as questões de gênero. História Revista, v. 19, n. 3, p. 33-58, 2014. Disponível em:

https://www.revistas.ufg.br/historia/article/view/32992. Acesso em: 16 jun. 2020.

TEPEDINO, Gustavo. Temas de Direito Civil. 3. ed. Rio de Janeiro: Renovar, 2004.

VALLADON, Simone Clapier. As teorias da personalidade. São Paulo: Martins Fontes, 1988. 